\title{
A Comparative Analysis of Chinese and Foreign Press Reports on Chinese Films -a Case Study of Reports on Wolf Warrior 2
}

\author{
Wang Cong-cong ${ }^{a}$, Ruan Xiao-tong ${ }^{b}$ \\ South China Business College, Guangdong University of Foreign Studies, Guangzhou, China, \\ 510000
}

awcporridge@163.com, b759700776@qq.com

Keywords: Attitude; BBC; China Daily; Wolf Warrior 2.

\begin{abstract}
This paper aims to analyze appraisal resources in reports of China Daily and BBC commenting on Wolf Warrior 2. Under the framework of Appraisal Theory, the author classifies the appraisal resources in two news discourses. It is revealed that the total amount of attitudinal resources of BBC is more than that of China Daily. The Appreciation resources are most frequently used in two reports, which show that the news writers prefer to aesthetic evaluation; the Judgment and Affect resources in the BBC are used more often than those in China Daily, which indicates that the news writer of BBC is more subjective when commentating on Wolf Warrior 2.
\end{abstract}

\section{Introduction}

Wolf Warrior 2, a modern military action film directed by Wu Jing, gained a positive response in Chinese and foreign film markets and earned a high score on review aggregation sites. Against this background, it has been appraised by many mainstream media in different countries. As an institution of disclosing information and imparting knowledge, media have been an indispensable part of our daily life and exercised an arguably massive impact on our perception towards and actions in the worldly life. On the other hand, although almost all media claim their reports to be objective, fair and moderate, the lexicon in reports may reveal partial and ambivalent positions and attitudes of the writers. The ideology created and hidden in those reports is like some kind of mysterious spell cast on the readers and changes their attitudes towards some phenomenon which might otherwise have been positively or negatively evaluated by themselves before reading those reports. This intriguing and annoying credit of remaking the society should go to language, the most confusing target of scientific study in terms of its interplay with the society. This is one of the most important reasons why many critics observe that most reports are misleading and distrusting. In other words, what we read may not reveal the truth we want to be dawned upon. In this sense, cross-cultural studies of discourses are of paramount importance in that they provide us with different perspectives to see the world around us, which forms the most core part of our comparative study between Chinese and Britain media institutions commenting on the same Chinese movie.

\section{An overview of Appraisal System}

The theory this paper employs is Appraisal theory developed by Martin and White [1]. As an extension of the interpersonal function of Systemic Functional Linguistics (SFL), Appraisal theory is more applied to interpretive studies while SFL to explanatory studies [2]. It examines how "discourse or speakers express, negotiate and naturalize the relationship among specific subjects and language resources of ideology" [3]. Under this framework, the interpersonal meanings can be organized into different systems: Attitude, Engagement, Graduation, which can further be divided into different sub-systems. As this paper only focuses on the attitudinal resources, the sub-systems of Engagement and Graduation will not expounded in detail. Attitude is a comprehensive term categorizing Affect, Judgement, and Appreciation, all of which have positive and negative values. Affect is about the way positive or negative feelings are expressed in the discourse; Judgement 
differs between personal evaluation, moral evaluation and legal evaluation of behaviors; Appreciation deals with the aesthetic evaluation of abstract and natural things [4].

\section{About the data}

Since there have been scores of press reports on Wolf Warrior 2 for a long period and these reports vary in content, it is difficult for the authors to study all the press reports due to limited time and energy. Therefore, this paper only selects two reports from BBC and China Daily for a pilot study. The title of the report in the BBC is "Wolf Warrior 2: The nationalist action film storming China" and the one in China Daily is "Wolf Warrior 2 promotes how China will always protect its nationals". Both reports can be downloaded from the official websites of the institutions.

As a British public service, BBC enjoys a high reputation with regard to the objectivity of its reports. China Daily, the only state-run English-language newspaper in China, started publication in 1981, covering more than 900 thousands global issues. It plays an important role in publicity and becomes an important platform of information inquiry for China.

\section{Analysis and discussion}

Press reports are written by news writers who make a statement of the event and give an evaluative analysis to the relevant aspects of the event. This chapter classifies and sorts the extracted appraisal resources based on the sub-system of Attitude, and displays the statistics in the form of tables and makes a detailed analysis of the statistics.

\subsection{Attitudinal resources in BBC's report}

Across the selected news report of BBC, the theme in clauses is realized by different subjects such as action film, box office, China, Chinese, Wu Jing etc.. All these subjects are either the direct participants in relevant processes or the evaluated objects. The proportions of each sub-system of Attitude in the discourse are shown in the table below.

Table 1 Distribution of Attitudinal Resources in BBC

\begin{tabular}{|c|c|c|c|c|c|}
\hline System & \multicolumn{2}{|c|}{ Feature } & Numbers & \multicolumn{2}{|c|}{ proportion } \\
\hline Attitude-type & \multicolumn{2}{|c|}{ Affect } & 8 & \multicolumn{2}{|c|}{$34.9 \%$} \\
\hline & \multicolumn{2}{|c|}{ Judgment } & 6 & \multicolumn{2}{|c|}{$26 \%$} \\
\hline & \multicolumn{2}{|c|}{ Appreciation } & 9 & \multicolumn{2}{|c|}{$39.1 \%$} \\
\hline & \multicolumn{2}{|c|}{ Appieciduon } & 23 & \multicolumn{2}{|c|}{$100 \%$} \\
\hline \multicolumn{3}{|c|}{ Word } & 195 & \multicolumn{2}{|c|}{$100 \%$} \\
\hline \multirow[t]{3}{*}{ Affect } & \multicolumn{2}{|c|}{ quality } & 6 & \multicolumn{2}{|c|}{$75 \%$} \\
\hline & \multicolumn{2}{|c|}{ process } & 2 & \multicolumn{2}{|c|}{$25 \%$} \\
\hline & \multicolumn{2}{|c|}{ comment } & 0 & \multicolumn{2}{|c|}{$0 \%$} \\
\hline \multirow[t]{5}{*}{ Judgment } & \multirow[t]{3}{*}{ social esteem } & normality & 0 & $0 \%$ & \multirow[t]{3}{*}{$66.7 \%$} \\
\hline & & capacity & 3 & $75 \%$ & \\
\hline & & tenacity & 1 & $25 \%$ & \\
\hline & \multirow{2}{*}{$\begin{array}{c}\text { social } \\
\text { sanction }\end{array}$} & veracity & 2 & $100 \%$ & \multirow[t]{2}{*}{$33.3 \%$} \\
\hline & & propriety & 0 & $0 \%$ & \\
\hline \multirow[t]{3}{*}{ Appreciation } & \multicolumn{2}{|c|}{ reaction } & 4 & \multicolumn{2}{|c|}{$44.4 \%$} \\
\hline & \multicolumn{2}{|c|}{ composition } & 1 & \multicolumn{2}{|c|}{$11.2 \%$} \\
\hline & \multicolumn{2}{|c|}{ valuation } & 4 & \multicolumn{2}{|c|}{$44.4 \%$} \\
\hline
\end{tabular}

As is shown in the table above, 23 attitudinal resources are used in the overall evaluation of the film, among which Affect is the most frequently used resource, accounting for 34.9 percent; Appreciation resources take the second place, accounting for 39.1 percent; Judgment resources take the third with 26 percent. In other words, Appreciation resources are the main appraisal resources and Affect resources are placed in the middle while the frequencies of Judgment are the lowest in the BBC report of Wolf Warrior 2. The press reports are for the general public, thus the news writers need to be objective. Appreciation is a relative objective category by applying aesthetic and social value to the evaluation objects. However, as a subjective category, the frequent use of Affect 
resources will weaken the objectivism and fairness of press reports to some extent, which is worth being further analyzed.

\subsection{Attitudinal resources in China Daily's report}

The same event has been evaluated differently in China Daily. With the same analysis pattern of the report in BBC about Wolf Warrior 2, it is easy to carry out an analysis of appraisal resources on the report in China Daily. The table below provides the distributions of each sub-systems of Attitude in the report about Wolf Warrior 2 of China Daily.

Table 2 Distribution of Attitudinal Resources in China Daily

\begin{tabular}{|c|c|c|c|c|c|}
\hline System & \multicolumn{2}{|c|}{ Feature } & Numbers & \multicolumn{2}{|c|}{ proportion } \\
\hline \multirow[t]{3}{*}{ Attitude-type } & \multicolumn{2}{|c|}{ Affect } & 5 & \multicolumn{2}{|c|}{$24 \%$} \\
\hline & \multicolumn{2}{|c|}{ Judgment } & 4 & \multicolumn{2}{|c|}{$19 \%$} \\
\hline & \multicolumn{2}{|c|}{ Appreciation } & 12 & \multicolumn{2}{|c|}{$57 \%$} \\
\hline \multicolumn{3}{|c|}{ Total } & 21 & \multicolumn{2}{|c|}{$100 \%$} \\
\hline \multicolumn{3}{|c|}{ Words } & 244 & \multicolumn{2}{|c|}{$100 \%$} \\
\hline \multirow[t]{3}{*}{ Affect } & \multicolumn{2}{|c|}{ quality } & 4 & \multicolumn{2}{|c|}{$80 \%$} \\
\hline & \multicolumn{2}{|c|}{ process } & 0 & \multicolumn{2}{|c|}{$0 \%$} \\
\hline & \multicolumn{2}{|c|}{ comment } & 1 & \multicolumn{2}{|c|}{$20 \%$} \\
\hline \multirow[t]{5}{*}{ Judgment } & \multirow[t]{3}{*}{ social esteem } & normality & 1 & $33.3 \%$ & \multirow[t]{3}{*}{$75 \%$} \\
\hline & & capacity & 2 & $66.7 \%$ & \\
\hline & & tenacity & 0 & $0 \%$ & \\
\hline & \multirow{2}{*}{$\begin{array}{c}\text { social } \\
\text { sanction }\end{array}$} & veracity & 0 & $0 \%$ & \multirow[t]{2}{*}{$25 \%$} \\
\hline & & propriety & 1 & $25 \%$ & \\
\hline \multirow[t]{3}{*}{ Appreciation } & \multicolumn{2}{|c|}{ reaction } & 4 & \multicolumn{2}{|c|}{$33.3 \%$} \\
\hline & \multicolumn{2}{|c|}{ composition } & 1 & \multicolumn{2}{|c|}{$8.3 \%$} \\
\hline & \multicolumn{2}{|c|}{ valuation } & 7 & \multicolumn{2}{|c|}{$58.4 \%$} \\
\hline
\end{tabular}

The above table shows that there are 21 attitudinal resources in the China Daily's report. Among the three sub-systems, the occurrence of Appreciation is the highest one, accounting for 57 percent, and the proportion of Affect is much less than that of Appreciation, with only 24 percent. As the analysis in the previous section, the degree of subjectivity of Affect is relatively high, and the news writer tends to use less Affect to express his/her attitude about the film. And Appreciation resources are used more often to describe the characters, scene and other aspects of the film due to its objective nature. Judgement is the least, which takes up 19 percent.

\subsection{Comparison and discussion}

Following the previous analyses, the author moves on to conduct a comparative analysis of the distribution of attitudinal resources in BBC and China Daily reports of Wolf Warrior 2. The results are shown in the following table.

Table 3 Comparison of Attitude in BBC and China Daily

\begin{tabular}{|c|c|c|c|c|}
\hline \multirow{2}{*}{} & \multicolumn{2}{|c|}{ BBC } & \multicolumn{2}{c|}{ China Daily } \\
\cline { 2 - 5 } & Numbers & proportion & Numbers & proportion \\
\hline Affect & 8 & $34.9 \%$ & 5 & $14.3 \%$ \\
\hline Judgment & 6 & $26 \%$ & 4 & $19 \%$ \\
\hline Appreciation & 9 & $39.1 \%$ & 12 & $66.7 \%$ \\
\hline Attitude & 23 & $100 \%$ & 21 & $100 \%$ \\
\hline words & \multicolumn{2}{|c|}{195} & 244 \\
\hline
\end{tabular}

According to Table 3, the distribution of attitudinal resources, in general, show some similarity and differences between BBC report and China Daily report. First, the attitudinal resources in China Daily report are fewer than those in the BBC report. Second, these two reports prefer to use Appreciation and Affect. However, the distribution of the three sub-systems is completely different. Each kind of Attitude is roughly evenly distributed in the BBC report. However, there exists a clear difference in China Daily report where Appreciation resources are used much more often than the other two. Appreciation resources are most frequently used in both of BBC and China Daily, 
indicating that social value is the most used parameter for these two media when commentating on films. Judgment resources have been adopted more in BBC than in China Daily, which indicates $\mathrm{BBC}$ writer is likely to pay more attention to the story and characters of the film than China Daily writer. Affect resources in BBC are more than those in China Daily. The frequent use of Affect resources reveals that the $\mathrm{BBC}$ writer has a stronger subjective tone in commentating on Wolf Warrior 2 than the China Daily writer. In a word, these two media have different tendency when they use attitudinal resources in commentating on Chinese film Wolf Warrior 2, which indicates that these two media represent two different cultural paradigms.

\section{Conclusion}

There are some differences between China and Britain in value pursuit and ethical orientation. Through presenting different Chinese and Western ideologies, the film highlights the cultural differences. In China, mainstream films promoting patriotism emphasize solidarity among individuals, groups and countries, while Wolf Warrior 2 expresses personal heroism of Leng Feng [5]. According to Stanley Rosen, a professor at the University of Southern California who studies Chinese society and cinema, Wolf Warrior 2 is a very individualist personal quest, which is much more of a Hollywood type. In most Hollywood blockbusters, superhero character is definitely an important feature. As the representative of the western films, Hollywood films promote freedom and individualism. Therefore, different value pursuit reveals different forms in displaying patriotism in Chinese films and Western films. The Chinese film Wolf Warrior 2 imitates Hollywood blockbusters to shape a superhero character, which is, however, not well accepted by some foreign mainstream media like BBC and perhaps the audience.

\section{Acknowledgements}

This paper was funded by the English Language \& Literature, one of the Key Programs in Guangdong 2016 (GDTX170109), and the Association Project of Comparative Study of English and Chinese in the New Era (NG2017298).

\section{References}

[1] J. R. Martin, P. R. R. White. The Language of Evaluation: Appraisal in English. New York: Palgrave Macmillan, 2005.

[2] Zhenhua Wang. Appraisal System and their Operation: A New Development in the Systemic Functional Linguistics. Journal of Foreign Languages, 2001(6): 13-20.

[3] Zhuanglin Hu, Yongsheng Zhu etc. An Introduction to Systemic Functional Grammar. Beijing: Peking University Press, 2005: 49-195.

[4] J. R. Martin, D. Rose. Working with Discourse: Meaning Beyond the Clause. London: Continuum, 2003.

[5] Lijing Meng. Chinese Film of Military Theme in the Blockbuster Era: Symposium Overview on Wolf Warriors. Contemporary Cinema, 2015(5): 191-193. 